\title{
Trauma Surgery $\&$ Acute Care Open \\ Thefeasibility, appropriateness, and applicability of trauma scoring systems in low and middle-income countries: a systematic review
}

\author{
Isabelle Feldhaus, ${ }^{1}$ Melissa Carvalho (D , ${ }^{2}$ Ghazel Waiz, ${ }^{3}$ Joel Igu, ${ }^{4}$ Zachary Matthay, ${ }^{3}$ \\ Rochelle Dicker, ${ }^{2}$ Catherine Juillard ${ }^{2}$
}

\begin{abstract}
- Additional material is published online only. To view please visit the journal online (http://dx.doi.org/10.1136/ tsaco-2019-000424).

'Department of Global Health and Population, Harvard University T H Chan School of Public Health, Boston, Massachusetts, USA 2Department of Surgery, University of California Los Angeles, Los Angeles, California, USA

${ }^{3}$ Department of Surgery, Center for Global Surgical Studies, University of California San Francisco, San Francisco,

California, USA

${ }^{4}$ Johns Hopkins University Carey Business School, Baltimore, Maryland, USA
\end{abstract}

Correspondence to Dr Rochelle Dicker, Department of Surgery, University of California, Los Angeles, CA 90095, USA; RDicker@mednet. ucla.edu

Received 6 December 2019 Revised 27 March 2020 Accepted 17 April 2020 (c) Author(s) (or their employer(s)) 2020. Re-use permitted under CC BY-NC. No commercial re-use. See rights and permissions. Published by BMJ.

To cite: Feldhaus I,

Carvalho M, Waiz G, et al.

Trauma Surg Acute Care Open 2020:5:e000424.

\section{ABSTRACT}

Background About 5.8 million people die each year as a result of injuries, and nearly $90 \%$ of these deaths occur in low and middle-income countries (LMIC). Trauma scoring is a cornerstone of trauma quality improvement (QI) efforts, and is key to organizing and evaluating trauma services. The objective of this review was to assess the appropriateness, feasibility, and QI applicability of traditional trauma scoring systems in LMIC settings.

Materials and methods This systematic review searched PubMed, Scopus, CINAHL, and trauma-focused journals for articles describing the use of a standardized trauma scoring system to characterize holistic health status. Studies conducted in high-income countries (HIC) or describing scores for isolated anatomic locations were excluded. Data reporting a score's capacity to discriminate mortality, feasibility of implementation, or use for QI were extracted and synthesized.

Results Of the 896 articles screened, 336 were included. Over half of studies (56\%) reported Glasgow Coma Scale, followed by Injury Severity Score (ISS; 51\%), Abbreviated Injury Scale (AIS; 24\%), Revised Trauma Score (RTS; 19\%), Trauma and Injury Severity Score (TRISS; 14\%), and Kampala Trauma Score (7\%). While ISS was overwhelmingly predictive of mortality, 12 articles reported limited feasibility of ISS and/or AIS. RTS consistently underestimated injury severity. Over a third of articles (37\%) reporting TRISS assessmentsobserved mortality that was greater than that predicted by TRISS. Several articles cited limited human resources as the key challenge to feasibility.

Conclusions The findings of this review reveal that implementing systems designed for HICs may not be relevant to the burden and resources available in LMICs. Adaptations or alternative scoring systems may be more effective.

PROSPERO registration number CRD42017064600.

\section{INTRODUCTION}

About 5.8 million people die each year as a result of injuries, and nearly $90 \%$ of these deaths occur in low and middle-income countries (LMIC). ${ }^{1}$ Improvements in the organization of trauma care have resulted in significant reductions in mortality in high-income countries (HIC), such as the USA and Canada. ${ }^{2}$ Likewise, there have been increasing efforts to improve trauma care management in LMICs.
Trauma scoring is a cornerstone of trauma care improvement interventions. Standardized trauma scoring systems allow for appropriate triage and classification of trauma patients as well as prediction of patient outcomes and risk adjustment when evaluating patient outcomes and hospital performance. ${ }^{3}$ They enable programs to highlight opportunities for trauma care improvement, including among such as identification of observed mortality among patients with low injury severity that may be higher than predicted, as well as to compare trauma outcomes against established norms. ${ }^{4}$ They can thus provide an objective definition for preventable deaths and indicate probability of survival, acting as the foundation for mortality review conferences, audit filters, and other quality improvement (QI) initiatives. ${ }^{4}$

Several trauma scoring systems have been developed and validated in the past 50 years, including the Injury Severity Score (ISS), Abbreviated Injury Scale (AIS), Revised Trauma Score (RTS), and Trauma and Injury Severity Score (TRISS), among others (figure 1). ${ }^{4}$ Each type of score was developed with distinct purposes across the continuum of care. The majority of trauma scoring systems were developed for resource-rich settings, however, and often require regular access to advanced diagnostics. Few have been validated for use in LMICs. In fact, studies consistently demonstrate that many scoring systems underpredict mortality in these settings. ${ }^{5-12}$ As a result, physiological-based systems, such as the Kampala Trauma Score (KTS), have been developed and shown to be valid triage tools to predict patient outcomes and inform decision-making. ${ }^{13-15}$

Despite evidence that certain trauma scoring systems may not be appropriate for resourcelimited settings, those commonly found in HICs may also be used in LMICs because they remain the most well established and accepted for trauma management. Yet, the extent to which each scoring system is used in LMICs around the world remains unknown. Understanding which and how trauma scoring systems are used is the first step in determining which score(s) may be optimal in these settings. The optimal trauma score for any setting will strike the appropriate balance between accuracy in quantifying injury severity and feasibility in implementation. The objective of this review was to identify scores that have been used in LMICs to classify injury severity and assess their 


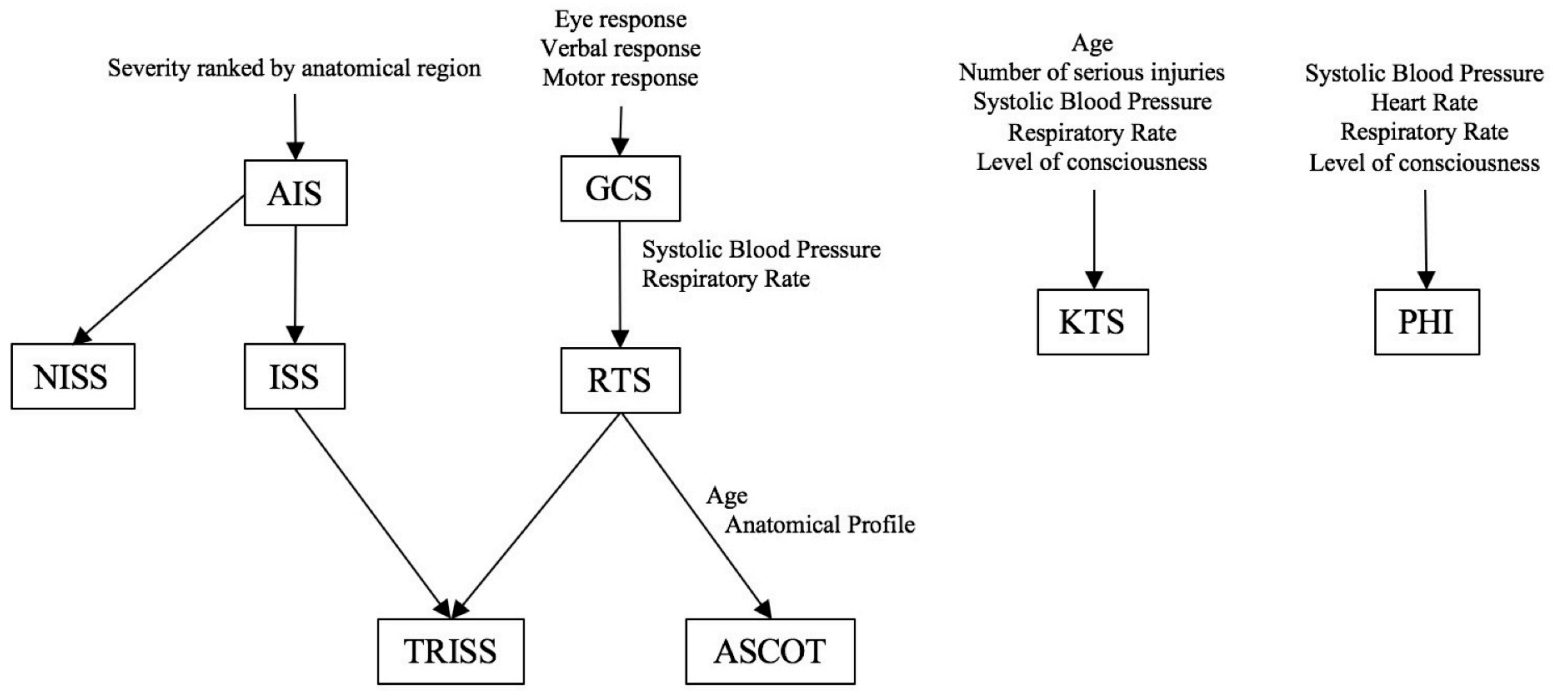

Figure 1 Relational schema of existing trauma scoring systems. Boxes indicate a subset of standard trauma scoring systems reviewed here. Text outlines individual factors used to compute trauma score. Example: To compute AIS, injury severity is ranked by anatomic region. The computation of ISS is based on AIS assignment of each anatomic region. TRISS methodology incorporates ISS and RTS to predict probability of survival. AIS, Abbreviated Injury Scale; ASCOT, A Severity Characterization of Trauma; GCS, Glasgow Coma Scale; ISS, Injury Severity Score; KTS, Kampala Trauma Score; NISS, New Injury Severity Score; PHI, Prehospital Index; RTS, Revised Trauma Score; TRISS, Trauma and Injury Severity Score.

appropriateness, feasibility, and application in QI efforts in these settings.

\section{MATERIALS AND METHODS \\ Search strategy}

Electronic databases PubMed, Scopus, and CINAHL as well as selected academic journals were searched for relevant articles published since 1990. The final database search was conducted on November 13, 2017. Search queries used MeSH (Medical Subject Headings) and keywords, including 'injury', 'trauma', 'severity', 'score', 'low and middle income countries' and scorespecific terms (online supplementary appendix 1). Countries were classified as LMICs according to the World Bank country income classifications. ${ }^{16}$ Articles describing the use of a standardized trauma or injury scoring system to characterize holistic health status were eligible for inclusion. Studies were limited to those published in English or French. Studies conducted in HICs were not included.

Articles describing the use of scoring systems for isolated organ systems and/or anatomic locations were excluded. Articles describing the use of Glasgow Outcome Scale (GOS) without reference to the use of Glasgow Coma Scale (GCS) were not included in this review, since GOS is primarily used to classify patients with brain injuries. GCS is used to evaluate overall consciousness as a component of trauma scoring systems and was, therefore, included in this review. Emotional trauma and psychiatric-related scoring systems were excluded.

Titles and abstracts of search results were screened for eligibility and the selected full-text articles were obtained. Articles that stated that no trauma scoring system was available were noted as a proxy for feasibility, though not included in data analyses. The references of included articles were screened to identify additional articles not initially captured in initial searches to ensure robustness of the study. Retrieved records were imported into Microsoft Excel 2016 and Mendeley V.1.17.10

\section{Data extraction and analysis}

Two authors independently reviewed each full-text article and extracted the following information: publication year, country setting, study objective, study design, sample size, and trauma score(s) reported. Studies were categorized into: (1) those reporting or using a trauma score without further evaluation of the system, and (2) those evaluating the trauma scoring system. Articles in the second category underwent a quality (bias) assessment using a standardized critical appraisal checklist (online supplementary appendix 2) adapted from Fowkes and Fulton and Liberman et al. ${ }^{17} 18$ Discrepancies between reviewers were resolved by discussion and consensus. In the event that no consensus was reached, a third party acted as an arbiter.

Descriptive statistics of study characteristics were generated by country, world region, and type of scoring system. For articles reporting evaluations of scoring systems, data on a trauma score's capacity to discriminate mortality, feasibility of implementation, or use in QI efforts were extracted. Meta-analysis was deemed inappropriate due to the wide diversity of primary outcomes and study designs among the articles included for review.

\section{RESULTS}

Of the 896 articles screened, 336 reporting trauma scores in LMICs were included in this review (figure 2). The reporting of trauma scores in published studies generally increased over time, except in recent years (figure 3). Among the 50 countries represented, a majority of articles focused on South Africa (52 studies), followed by Nigeria (40 studies), India (28 studies), Iran (28 studies), and Malaysia (26 studies). Studies most often focused on upper middle-income countries (165 studies; 49\%) and lower middle-income countries (135 studies; 40\%), whereas low-income settings composed only 16\% (53 studies) of reviewed articles (figure 4).

Over half of studies (187 studies; 56\%) reported GCS among their assessments of trauma severity, followed by ISS (173 studies; 51\%), AIS (81 studies; 24\%), RTS (65 studies; 19\%), and TRISS (47 studies; 14\%). KTS (24 studies; 7\%) was reported 


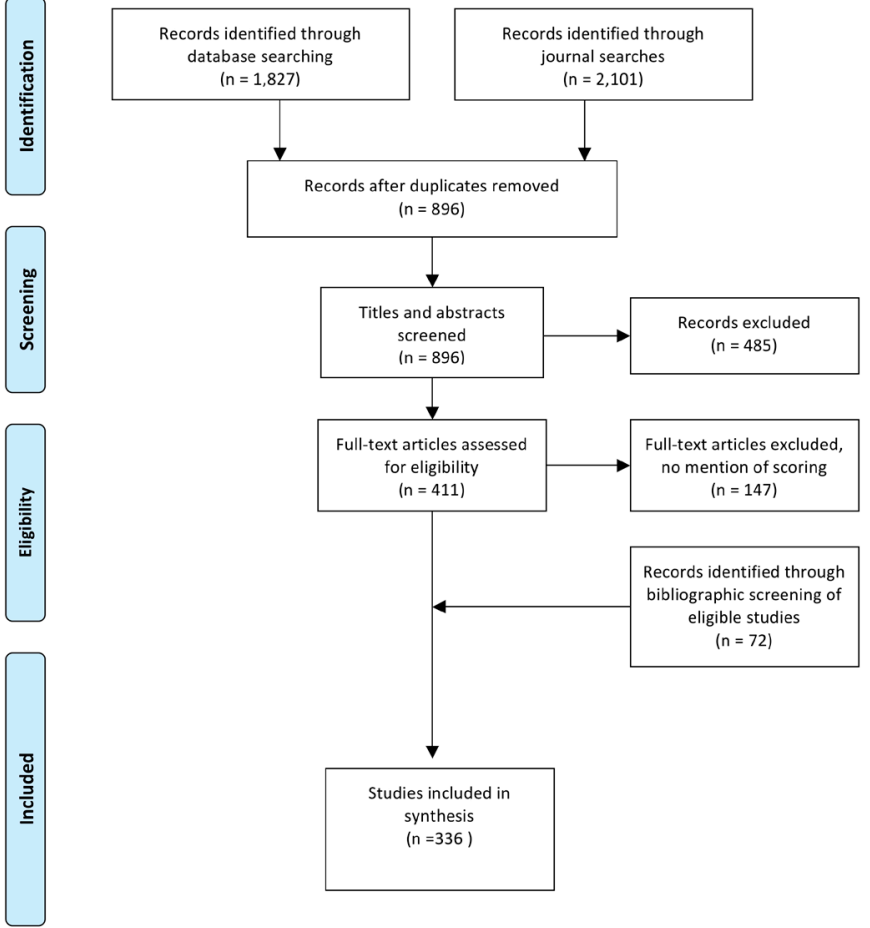

Figure 2 Preferred Reporting Items for Systematic Reviews and MetaAnalyses (PRISMA) flow diagram.

least often. Other miscellaneous scoring systems, such as indirect stratification based on urgency, victim perception, or other proxy measures, were reported in 11\% (37 studies) of articles. Over $33 \%$ (112 studies) of articles reported quantitative results on at least one of these features, most commonly reporting differences in score means between population groups, ORs associating trauma scores with mortality, or predictive power using receiver operating characteristic analysis.

\section{Capacity to predict mortality}

Seventy articles reported on the relationship between ISS and mortality (online supplementary file 3). Of these, 43 articles $(61 \%)$ reported ISS to be a good or strong predictor of death in their population samples. ${ }^{7} 19202122-24252627282930-323334353637$

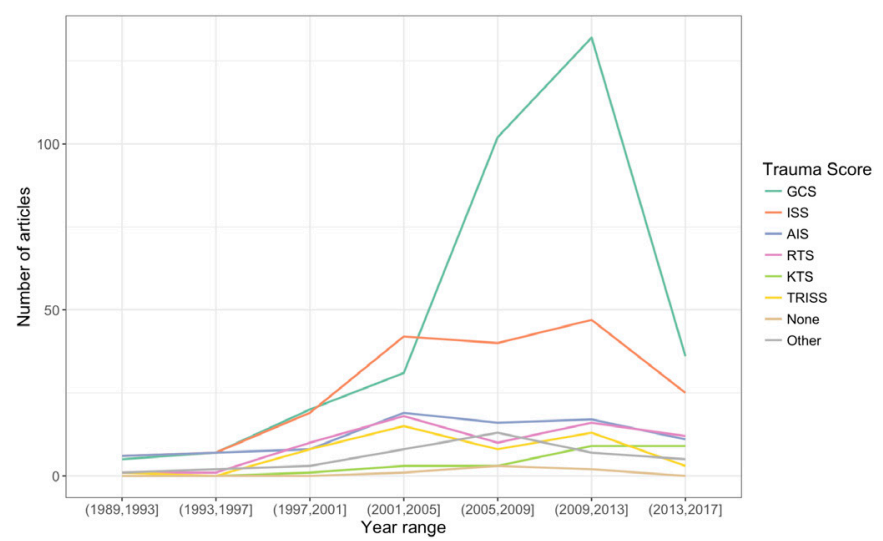

Figure 3 Published studies reporting trauma scores in low and middle-income countries (LMIC) by year. AIS, Abbreviated Injury Scale; GCS, Glasgow Coma Scale; ISS, Injury Severity Score; KTS, Kampala Trauma Score; RTS, Revised Trauma Score; TRISS, Trauma and Injury Severity Score.

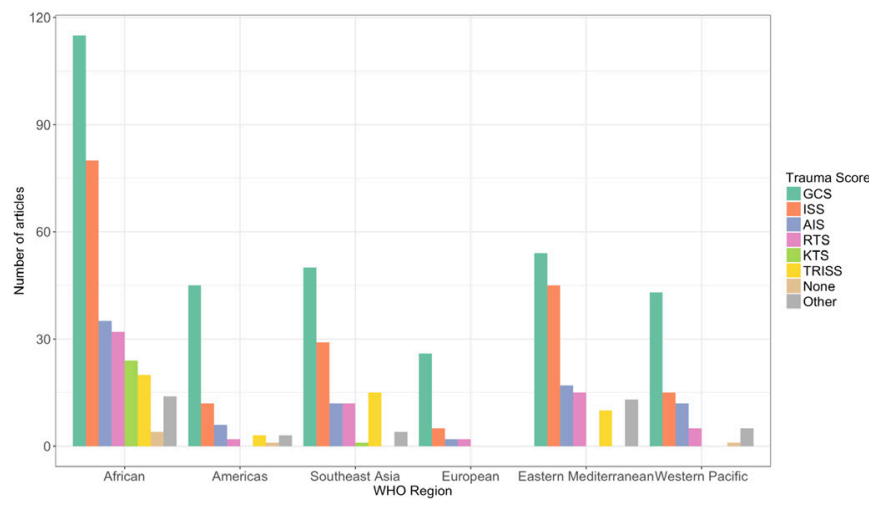

Figure 4 Published studies reporting trauma scores in low and middle-income countries (LMIC) by WHO region. AIS, Abbreviated Injury Scale; GCS, Glasgow Coma Scale; ISS, Injury Severity Score; KTS, Kampala Trauma Score; RTS, Revised Trauma Score; TRISS, Trauma and Injury Severity Score.

$38394041424344 \quad 45-515253545556575859$ Fourteen articles reported ISS to be a weak predictor of mortality. ${ }^{10} 12146061626364656667-69$ ${ }^{70}$ Articles noting that ISS was not significantly associated with mortality had considerable missing data or very small sample sizes. ${ }^{71} 72$ Among the six articles evaluating multiple scoring systems, two articles reported that ISS was the weakest predictor of mortality compared with other measures evaluated. ${ }^{1273}$ In two other articles, the relationship between mortality and ISS was implicitly accepted and reported that moderate or severe ISS was the reason for increased mortality. ${ }^{19}{ }^{20}$ Of the seven articles that evaluated the use of AIS, ${ }^{74}$ four (57\%) reported that the score was a significant or valid predictor of mortality. ${ }^{2175-77}$ One study reported that AIS was strongly associated with hospital admission, and another confirmed a significant relationship between AIS score and injury severity. ${ }^{22} 78$

Among the 24 articles evaluating the predictive power of RTS (online supplementary file 3 ), 18 (75\%) reported a significant inverse relationship with mortality. ${ }^{7} 12 \quad 13 \quad 1473 \quad 23-26283031337934$ 357080 Another article reported that RTS was similar to AIS, KTS, and the South African Triage Scale when predicting in-hospital mortality. ${ }^{13}$ Of the 15 studies that evaluated the predictive performance of KTS 10 (68\%) reported it to be among the main predictors of mortality. ${ }^{12} 13-157379818283848570868788$ Two of these 10 studies (20\%) noted that KTS equally predicted mortality compared with other scores, such as RTS, ISS, AIS, TRISS, and GCS. ${ }^{13} 14$ Other scores that were reported to be significant predictors of mortality in the context studied included SAPS II (Simplified Acute Physiology Score), PRISM (Pediatric Risk of Mortality), Physiologic Severity Score, and PTS (Pediatric Trauma Score) .23246061

Of the 27 articles reporting TRISS assessments (online supplementary file 3), 9 studies indicated that the score provided a good estimation of survival probability, ${ }^{9}$ 26-28 3089909192 while 5 studies found it to be a moderate or weak predictor. ${ }^{14} 73347093$ At least 10 studies observed mortality that was greater than that predicted by TRISS..$^{810} 72759425959650$ For example, a study in Iran predicted $3.1 \%$ mortality using the TRISS method and observed 8\% mortality. ${ }^{94}$ Another study in India predicted $15.7 \%$ mortality, but observed $33.3 \%$ mortality among trauma patients. ${ }^{25}$ A prospective study in Uganda reported that 25 of 39 deaths were unexpected according to TRISS methodology, and that 24 of these deaths were deemed preventable by peer review. ${ }^{95}$ Only three articles (11\%) reported that TRISS was a good predictor of mortality. ${ }^{142627}$ Seven articles (25\%) explicitly 


\begin{tabular}{|c|c|c|c|c|c|c|c|c|c|}
\hline \multirow[b]{2}{*}{$\begin{array}{l}\text { Trauma } \\
\text { score }\end{array}$} & \multicolumn{3}{|l|}{ Opportunities } & \multicolumn{5}{|l|}{ Constraints } & \multirow[b]{2}{*}{ References } \\
\hline & $\begin{array}{l}\text { Good clinical } \\
\text { assessment }\end{array}$ & $\begin{array}{l}\text { Triage } \\
\text { tool }\end{array}$ & $\begin{array}{l}\text { Sufficient } \\
\text { data }\end{array}$ & $\begin{array}{l}\text { Lack of } \\
\text { equipment }\end{array}$ & $\begin{array}{l}\text { Lack of } \\
\text { human } \\
\text { resources }\end{array}$ & $\begin{array}{l}\text { Insufficient/ } \\
\text { poor-quality } \\
\text { data }\end{array}$ & $\begin{array}{l}\text { Inappropriate } \\
\text { for population }\end{array}$ & $\begin{array}{l}\text { Used } \\
\text { modified } \\
\text { version }\end{array}$ & \\
\hline ISS & & & & $\checkmark$ & $\checkmark$ & $\checkmark$ & $\checkmark$ & $\checkmark$ (elSS) & $7313273757790102103112-114$ \\
\hline AIS & & & & $\checkmark$ & & $\checkmark$ & & & 75102115 \\
\hline RTS & & & & & & $\checkmark$ & & $\checkmark$ & 1279103116 \\
\hline KTS & $\checkmark$ & $\checkmark$ & $\checkmark$ & & & & & & 12157382 \\
\hline TRISS & $\checkmark$ & & & $\checkmark$ & & $\checkmark$ & $\checkmark$ & $\checkmark$ & 27283473759395106107 \\
\hline
\end{tabular}

AIS, Abbreviated Injury Scale; eISS, estimated ISS; ISS, Injury Severity Score; KTS, Kampala Trauma Score; RTS, Revised Trauma Score; TRISS, Trauma and Injury Severity Score.

reported that the TRISS model did not accurately predict survival of trauma patients in their settings because the Major Trauma Outcome Study (MTOS) cohort was not the appropriate standard given the resources available (). ${ }^{102528-307596}$

\section{Feasibility and appropriateness in implementation}

Five articles specifically stated that no trauma scoring was used, with one study noting that a lack of available information made any kind of physiological scoring impossible. ${ }^{97-101}$ These studies were conducted in Botswana, Burkina Faso, Ghana, Mexico, South Africa, and Vietnam. The authors pointed to specific challenges and constraints of trauma scoring that may contribute to inaccuracies in survival probability estimates and/or underestimation of injury severity. These barriers included a lack of equipment, human resources, and poor record keeping which in turn resulted in insufficient or poor-quality data (table 1 ).

Twelve articles commented on the limited feasibility of ISS and/or AIS due to limited technological capacity. That appropriate AIS coding requires diagnostic or radiographic procedures, such as accurate CT scans, was also a common constraint. One research group reported that patients referred to other facilities for treatment were coded conservatively because of lack of diagnostic or radiographic procedures needed for accurate coding, resulting in potentially underestimated injury severity. ${ }^{102}$ Assessing ISS may be also impossible due to a patient's inability to pay out-of-pocket costs associated with sophisticated investigation. ${ }^{31}$ In some cases, these limitations led to the use of an estimated ISS score, which is based only on information available at resuscitation and underestimates injury severity with lower discriminatory and calibration performance. ${ }^{32}$. 33 Studies that used ISS to assess injury severity retrospectively were only able to do so for as low as $8 \%$ and up to $73 \%$ of patients. ${ }^{12} 103$

Based on seven studies, RTS is inadequate for resourceconstrained settings, consistently underestimating injury severity. RTS is overly subject to interobserver variations due to limited ability to make sufficiently accurate physiological measurements. ${ }^{104}$ The score could be calculated for $2 \%$ to $35 \%$ of patients in retrospective analyses. ${ }^{12} 79$ 103-105 Although KTS was also limited in its functionality as a triage tool, it was reported to be a good retrospective classifier of injury severity. ${ }^{79}$ One retrospective study was able to use existing data to compute KTS for $35 \%$ of trauma patients. ${ }^{12}$

TRISS methodology remains limited by the aforementioned constraints to ISS and AIS. TRISS methodology consistently performed better when applied to high-income settings as opposed to LMICs. ${ }^{93}$ Three studies in Uganda, Thailand, and Indonesia indicated low M-statistics (0.791-0.843), suggesting that TRISS may not be appropriate for their settings. ${ }^{7295}$ On the other hand, studies in Pakistan, Iran, India, Nigeria, and
Kenya reported reasonably comparable M-statistics (ranging from 0.889 to 0.97 ) and, in the Kenya case, consistent and high performance across facilities. 10737589 106-108 TRISS methodology was often applied in prospective studies, which may point to challenges with missing or poor-quality data for retrospective analyses. Among prospective studies, TRISS could be applied to $88.6 \%$ to $98.0 \%$ of trauma patients. ${ }^{2875}$

\section{Usage in QI efforts}

Although few studies recounted how trauma scores had been used in QI processes several QI-related outcomes were reported to be positively correlated to key trauma scores (table 2). ${ }^{109} 110$ 111 One study, focused on hospital-based trauma QI in Pakistan, compares ISS, GCS, and RTS scores before and after the implementation of QI initiatives as a means of demonstrating clinical efficacy. ${ }^{33}$ A study in Nigeria compared RTS classification of injury severity with panel consensus on preventable deaths, finding that the different processes generated different conclusions: RTS-based classification determined that $81 \%$ of deaths were preventable, whereas panel consensus identified $22.1 \%$ of deaths as preventable. ${ }^{104}$

\begin{tabular}{|c|c|}
\hline Trauma score & Positive correlates \\
\hline ISS & $\begin{array}{l}\text { Incidence of organ dysfunction } \\
\text { Length of stay/prolonged or continued hospitalization } \\
\text { Morbidity } \\
\text { Postoperative complications } \\
\text { Severity/grades of anatomic-specific injuries }\end{array}$ \\
\hline AIS & $\begin{array}{l}\text { Hospital admission } \\
\text { Long-term functional outcomes } \\
\text { Severity/grades of anatomic-specific injuries }\end{array}$ \\
\hline RTS & $\begin{array}{l}\text { Hospital admission } \\
\text { Length of stay/prolonged or continued hospitalization } \\
\text { Morbidity } \\
\text { Nosocomial infections } \\
\text { Postoperative complications }\end{array}$ \\
\hline KTS & $\begin{array}{l}\text { Hospital admission* } \\
\text { Length of stay/prolonged or continued hospitalizationt } \\
\text { Prehospital transportation }\end{array}$ \\
\hline TRISS & $\begin{array}{l}\text { Length of stay/prolonged or continued hospitalization } \\
\text { Nosocomial infections }\end{array}$ \\
\hline
\end{tabular}

*Three studies reported KTS was a significant predictor of need for admission 131579 . one study reported KTS was poor in predicting need for admission. ${ }^{86}$ †Three studies reported KTS predicted longer hospitalization ${ }^{70117}$; one study reported KTS was not a good indicator of prolonged hospitalization. ${ }^{79}$ AIS, Abbreviated Injury Scale; ISS, Injury Severity Score; KTS, Kampala Trauma Score; RTS, Revised Trauma Score; TRISS, Trauma and Injury Severity Score. 
Using ISS to examine mortality patterns in the USA and Mexico, Arreola-Risa et al concluded that improvements in intensive care and other hospital-based technologies would be less efficacious in reducing overall trauma mortality than improvements in prevention, prehospital transport and care, and emergency room care. ${ }^{77}$ In Uganda, QI processes using TRISS methodology to identify unexpected deaths resulted in 25 cases subject to peer reviews..$^{95}$ This process identified critical errors in care management, including missed diagnoses, inadequate intravenous therapy, delayed surgery, and poor airway control. Because more than half of reviewed deaths were due to missed injuries, peers identified clinical evaluation and investigation as well as interpretation of radiological signs as key areas for improvement. In their TRISS analysis, Zargar et al partially attributed unsatisfactory quality of care to insufficient usage of ambulances, delayed transportation to hospitals, frequent referrals between facilities, and inadequate resuscitation by emergency services. ${ }^{106}$

\section{DISCUSSION}

This review reveals that GCS and ISS remain the prominent trauma scoring systems in LMICs. GCS may be often used because of its ease of implementation and because it remains a strong predictor of mortality. However, its focus on neurological state, though important, may not be sufficiently holistic to assess injury severity. It may assign low scores to injuries without immediate neurological effects that are, nonetheless, severe and cause mortality over time. This could pose problems for use in prehospital care or triage procedures.

ISS was generally a good to strong predictor of mortality. However, ISS was found to be the weakest relative to other trauma scoring systems, including RTS, KTS, NISS (New Injury Severity Score), and TRISS. Persistent challenges faced in implementation suggest that the computation of ISS in LMIC settings is not always accurate. AIS, and subsequently ISS, are limited in that they do not consider the effect of age and exclude all but the most serious injury in one body region. Studies noted that conservative estimates were made when appropriate resources were not available for complete assessment. A wide variety of injury combinations may correspond to different injury severity in reality, but generate similar ISS values. ${ }^{75}$ Moreover, the lack of imaging capacity may be a critical limitation to achieving more accurate ISS assessments in LMIC settings. Despite these issues, it remains the most commonly used score and is often implemented without validated adaptations for resource-constrained settings.

KTS has been highlighted in a number of articles as a viable, validated alternative that predicts mortality similarly to RTS and ISS. The authors cautioned its premature integration into clinical decision-making, but emphasized its capacity to discriminate injury severity using a minimal data set and relatively simple instrument. ${ }^{15} 7982$ Continued rigorous evaluation of KTS as a triage tool and its ability to discriminate mortality may bolster confidence in its validity. The failure of TRISS to accurately predict survival in retrospective studies suggests that facilities do not generally collect the data necessary to be effective. Furthermore, MTOS, the retrospective study of trauma epidemiology and outcomes conducted in the USA used by TRISS computations, may be an inappropriate standard to use in resourceconstrained settings. Modified TRISS coefficients generated from MTOS-like evaluations in LMICs are needed to improve injury severity assessments using this scoring system in these settings.
In several cases, limited human resources led to missing or poor-quality recording of patient characteristics and conditions. Sufficient staff is required for appropriate recording of data, such as vital signs, and consistent administration of a trauma database is time consuming and can require dedicated staff. ${ }^{73} 112113$ General recommendations included periodically reviewing collected data to improve the quality of trauma management and establish continuous surveillance at facilities. ${ }^{34}$ Plans to analyze injury patterns in LMICs should first examine the completeness of data sources and consider adjusting analyses for such resource constraints. ${ }^{113}$ Establishing sustainable trauma databases using local resources will also require finding key champions to promote culture change at an institutional level and impress the value of data collection among hospital personnel. The situation thus emphasizes the importance of health systems strengthening initiatives focused on capacity building to provide adequate training. Such initiatives can have both short and long-term impacts in trauma care for appropriate triage, monitoring, and QI.

Trauma scoring methods are key to QI programs. Though several studies noted that QI measures should be taken, trauma scores were not readily used in formal QI processes. This may be a missed opportunity as findings from a few studies suggest trauma scores may be useful tools for identifying preventable deaths and evaluating care processes in LMICs-measures that have the potential to generate context-appropriate interventions for trauma care improvement. ${ }^{33} 7795106$ Yet, barriers to change, such as cultural norms, education and training, or inadequate resources, may exist and need to be further explored through implementation research. Capitalizing on existing trauma scoring systems may be an efficient use of resources in developing trauma care in these settings.

Interpretations of this review should take into account a number of limitations. Its broad scope highlighted which scoring systems have been applied in LMICs and generally reports on their appropriateness across a range of populations and types of injuries. Understanding trauma scoring for specific populations, such as children or specific injuries, will require further disaggregating findings. Publication bias may also play a significant role. To determine which scoring systems are relevant to LMICs, it will be important to understand the shortcomings of particular trauma scores and which can most negatively affect the effectiveness and efficiency of care processes.

Lesser used scores may prove feasible and appropriate for LMICs though they remain understudied. Among prospective studies, it was difficult to discern whether reported systems were used regularly or only for the purposes of research. Identifying which systems remain in regular use beyond organized studies would better represent prevalence and feasibility of existing systems. Specifying whether trauma scoring systems were used nationally or by particular areas or regions of a country could highlight features that affect the implementation of scoring systems or other interventions.

\section{CONCLUSIONS}

Trauma care in LMICs has largely been guided by advancements of HICs in recent decades. Trauma scoring is a key tool across stages of trauma care and beyond, used for quality assurance and improvement, clinical governance, resource allocation, and research. Implementing systems designed for HICs may not be immediately relevant to the burden and resources available in LMICs. In multiple instances, adaptations or alternative scoring systems have been more appropriate in assessing trauma in such 
settings. Yet, the use of these systems remains limited. Future research should focus on determining the optimal trauma scoring system under resource constraints. As a tool to accurately identify the most severe cases, system bottlenecks, and preventable deaths, trauma scoring remains an underused means to informing care for the distinct burden, resources, and infrastructure available in LMIC settings.

Contributors $\mathrm{CJ}$ and RD conceived the study objectives and oversaw overall study design and implementation. IF and GW designed the search strategy and data acquisition procedures. IF, GW, JI, ZM, and MC implemented the screening of articles for eligibility for review as well as extracted data from relevant articles. IF with support from MC interpreted and synthesized the data as well as drafted the article. All authors reviewed and approved the final article.

Funding The authors have not declared a specific grant for this research from any funding agency in the public, commercial or not-for-profit sectors.

\section{Competing interests None declared.}

Patient consent for publication Not required.

Provenance and peer review Not commissioned; externally peer reviewed.

Open access This is an open access article distributed in accordance with the Creative Commons Attribution Non Commercial (CC BY-NC 4.0) license, which permits others to distribute, remix, adapt, build upon this work non-commercially, and license their derivative works on different terms, provided the original work is properly cited, appropriate credit is given, any changes made indicated, and the use is non-commercial. See: http://creativecommons.org/licenses/by-nc/4.0/.

ORCID iD

Melissa Carvalho http://orcid.org/0000-0002-9607-0999

\section{REFERENCES}

1 World Health Organization. Injuries and Violence: The Facts [Internet]. Geneva. 2014 http://apps.who.int/iris/bitstream/10665/149798/1/9789241508018_eng.pdf?ua= $1 \& u a=1 \& u a=1$

2 World Health Organization. Guidelines for essential trauma care [Internet]. 2015. http://www.who.int/violence_injury_prevention/publications/services/guidelines_ traumacare/en/ (9 Oct 2015).

3 Senkowski CK, McKenney MG. Trauma scoring systems: a review. J Am Coll Surg 1999;189:491-503.

4 Mock C, Juillard C, Brundage S, Goosen J, Joshipura M. Who releases guidelines for trauma quality improvement programmes. Inj Prev 2009;15:359.

5 Talwar S, Jain S, Porwal R, Laddha BL, Prasad P. Trauma scoring in a developing country. Singapore Med J 1999;40:386-8.

6 Hariharan S, Chen D, Parker K, Figari A, Lessey G, Absolom D, James S, Fraser O, Letsholathebe CT. Evaluation of trauma care applying TRISS methodology in a Caribbean developing country. J Emerg Med 2009;37:85-90.

7 Joosse P, Soedarmo S, Luitse JS, Ponsen KJ. Trauma outcome analysis of a Jakarta university hospital using the TRISS method: validation and limitation in comparison with the major trauma outcome study. trauma and injury severity score. J Trauma 2001;51:134-40

8 Murlidhar V, Roy N. Measuring trauma outcomes in India: an analysis based on TRISS methodology in a Mumbai university hospital. Injury 2004;35:386-90.

9 Khan A, Zafar H, Naeem SN, Raza SA. Transfer delay and in-hospital mortality of trauma patients in Pakistan. Int J Surg 2010;8:155-8.

10 Zafar H, Rehmani R, Raja AJ, Ali A, Ahmed M. Registry based trauma outcome: perspective of a developing country. Emerg Med J 2002;19:391-4.

11 Laytin AD, Dicker RA, Gerdin M, Roy N, Sarang B, Kumar V, Juillard C. Comparing traditional and novel injury scoring systems in a US level-I trauma center: an opportunity for improved injury surveillance in low- and middle-income countries. J Surg Res 2017;215:60-6.

12 Laytin AD, Kumar V, Juillard CJ, Sarang B, Lashoher A, Roy N, Dicker RA. Choice of injury scoring system in low- and middle-income countries: lessons from Mumbai. Injury 2015;46:2491-7.

13 Gardner A, Forson PK, Oduro G, Stewart B, Dike N, Glover P, Maio RF. Diagnostic accuracy of the Kampala trauma score using estimated abbreviated injury scale scores and physician opinion. Injury 2017;48:177-83.

14 Weeks SR, Juillard CJ, Monono ME, Etoundi GA, Ngamby MK, Hyder AA, Stevens KA. Is the Kampala trauma score an effective predictor of mortality in lowresource settings? A comparison of multiple trauma severity scores. World I Surg 2014;38:1905-11.

15 Kobusingye OC, Lett RR. Hospital-Based trauma registries in Uganda. J Trauma 2000;48:498-502.

16 World Bank Data Help Desk. World Bank Country and Lending Groups. https:// datahelpdesk.worldbank.org/knowledgebase/articles/906519-world-bank-countryand-lending-groups (7 Oct 2017).
17 Fowkes FG, Fulton PM. Critical appraisal of published research: introductory guidelines. BMJ 1991;302:1136-40.

18 Liberman M, Mulder D, Sampalis J. Advanced or basic life support for trauma: metaanalysis and critical review of the literature. J Trauma 2000;49:584-99.

19 Heidari P, Pedram H, Zarei MR, Reza ZM, Rasouli MR, Reza RM, Vaccaro AR, RahimiMovaghar V, Vafa R-M. Spinal fractures resulting from traumatic injuries. Chin J Traumatol 2010;13:3-9.

20 Zargar M, Karbakhsh M, Zareei MR, Moez Ardalan K. Patterns of assault: experience from an urban hospital-based study in a developing country. Iran Red Crescent Med J 2004;6:50-4.

21 Mefire AC, Pagbe JJ, Fokou M, Nguimbous JF, Guifo ML, Bahebeck J. Analysis of epidemiology, lesions, treatment and outcome of 354 consecutive cases of blunt and penetrating trauma to the chest in an African setting. S Afr J Surg 2010;48:90-3.

22 Kasantikul V, Ouellet JV, Smith TA. Head and neck injuries in fatal motorcycle collisions as determined by detailed autopsy. Annu Proc Assoc Adv Automot Med 2002;46:125-37.

23 Lema MK, Chalya PL, Mabula JB, Mahalu W. Pattern and outcome of chest injuries at Bugando medical centre in northwestern Tanzania. J Cardiothorac Surg 2011:6:7.

24 Husum H, Gilbert M, Wisborg T, Van Heng Y, Murad M. Rural prehospital trauma systems improve trauma outcome in low-income countries: a prospective study from North Iraq and Cambodia. J Trauma 2003;54:1188-96.

25 Deshmukh VU, Ketkar MN, Bharucha EK. Analysis of trauma outcome using the TRISS method at a tertiary care centre in Pune. Indian I Surg 2012;74:440-4.

26 Mengistu Z, Azaj A. Trauma severities scores and their prediction of outcome among trauma patients in two hospitals of Addis Ababa, Ethiopia. Ethiop Med J 2012;50:231-7

27 Thanapaisal C, Wongkonkitsin N, Seow O-TS, Rangsrikajee D, Jenwitheesuk K, Phugkhem A, Bhudisawadi V. Outcome of in-patient trauma cases: accident and emergency unit, Khon Kaen university. J Med Assoc Thai 2005;88:1540-4.

28 Joosse P, Smit G, Arendshorst RJ, Soedarmo S, Ponsen K-J, Goslings JC. Outcome and prognostic factors of traumatic brain injury: a prospective evaluation in a Jakarta university hospital. J Clin Neurosci 2009;16:925-8.

29 Saidi HS, Macharia WM, Ating'a JEO. Outcome for hospitalized road trauma patients at a tertiary hospital in Kenya. Eur J Trauma 2005:31:401-6.

30 Siritongtaworn P, Opasanon S. The use of trauma Score-Injury severity score (TRISS) at Siriraj Hospital: how accurate is it? J Med Assoc Thai 2009;92:1016-21.

31 Kaya E, Ozguc H, Tokyay R, Yunuk 0 . Financial burden of trauma care on a university hospital in a developing country. J Trauma 1999:47:572-5.

32 Juillard CJ, Stevens KA, Monono ME, Mballa GAE, Ngamby MK, McGreevy J, Cryer G, Hyder AA. Analysis of prospective trauma registry data in Francophone Africa: a pilot study from Cameroon. World I Surg 2014;38:2534-42.

33 Hashmi ZG, Haider AH, Zafar SN, Kisat M, Moosa A, Siddiqui F, Pardhan A, Latif A, Zafar H. Hospital-Based trauma quality improvement initiatives: first step toward improving trauma outcomes in the developing world. I Trauma Acute Care Surg 2013:75:60-8. discussion 68

34 Moini M, Rezaishiraz H, Zafarghandi MR. Characteristics and outcome of injured patients treated in urban trauma centers in Iran. J Trauma 2000;48:503-7.

35 Pereira BMT, Nogueira VB, Calderan TRA, Villaça MP, Petrucci O, Fraga GP. Penetrating cardiac trauma: 20-y experience from a university teaching hospital. J Surg Res 2013;183:792-7

36 Kesinger MR, Nagy LR, Sequeira DJ, Charry JD, Puyana JC, Rubiano AM. A standardized trauma care protocol decreased in-hospital mortality of patients with severe traumatic brain injury at a teaching hospital in a middle-income country. Injury 2014:45:1350-4.

37 Mock CN, Adzotor KE, Conklin E, Denno DM, Jurkovich GJ. Trauma outcomes in the rural developing world: comparison with an urban level I trauma center. J Trauma 1993;35:518-23.

38 Mock CN, Denno D, Adzotor ES. Paediatric trauma in the rural developing world: low cost measures to improve outcome. Injury 1993;24:291-6.

39 Abantanga FA, Mock CN. Childhood injuries in an urban area of Ghana a hospitalbased study of 677 cases. Pediatr Surg Int 1998;13:515-8.

40 London JA, Mock CN, Quansah RE, Abantanga FA, Jurkovich GJ. Priorities for improving hospital-based trauma care in an African City. J Trauma 2001;51:747-53.

41 Roy N, Gerdin M, Ghosh S, Gupta A, Kumar V, Khajanchi M, Schneider EB, Gruen R, Tomson G, von Schreeb J, et al. 30-Day in-hospital trauma mortality in four urban university hospitals using an Indian trauma registry. World I Surg 2016:40:1299-307.

42 Dharap SB, Kamath S, Kumar V. Does prehospital time affect survival of major trauma patients where there is no prehospital care? J Postgrad Med 2017;63:169.

43 Zargar M, Sayyar Roudsari B, Shadman M, Kaviani A, Tarighi P. Pediatric transport related injuries in Tehran: the necessity of implementation of injury prevention protocols. Injury 2003;34:820-4.

44 Zargar M, Khaji A, Karbakhsh M. Pattern of motorcycle-related injuries in Tehran, 1999 to 2000: a study in 6 hospitals. East Mediterr Health J 2006;12:81-7.

45 Wisborg T, Murad MK, Edvardsen O, Husum H. Prehospital trauma system in a low-income country: system maturation and adaptation during 8 years. J Trauma 2008;64:1342-8 
46 Jat AA, Khan MR, Zafar H, Raja AJ, Hoda Q, Rehmani R, Lakdawala RH, Bashir S. Peer review audit of trauma deaths in a developing country. Asian J Surg 2004;27:58-64.

47 Obalum DC, Enweluzo 0, Giwa SO. Morbidity and mortality associated with polytrauma at a Nigerian tertiary hospital. West Afr J Med 2008;27:97-100.

48 Elechi EN, Etawo SU. Pilot study of injured patients seen in the University of port Harcourt teaching Hospital, Nigeria. Injury 1990;21:234-8.

49 Botchey IM, Hung YW, Bachani AM, Paruk F, Mehmood A, Saidi H, Hyder AA. Epidemiology and outcomes of injuries in Kenya: a multisite surveillance study. Surgery 2017;162:\$45-53.

50 Saidi H, Mutisto BK. Motorcycle injuries at a tertiary referral hospital in Kenya: injury patterns and outcome. Eur J Trauma Emerg Surg 2013;39:481-5.

51 Sethi D, Aljunid S, Saperi SB, Zwi AB, Hamid H, Mustafa ANB, Abdullah AHA. Comparison of the effectiveness of major trauma services provided by tertiary and secondary hospitals in Malaysia. J Trauma 2002;53:508-16.

52 Shah AA, Rehman A, Shah SJ, Haider AH, Zogg CK, Zafar SN, Hadi YB, Zafar H. Abdominal gunshot wounds-a comparative assessment of severity measures. J Surg Res 2015:198:334-9.

53 Navsaria PH, de Bruyn P, Nicol AJ. Penetrating abdominal vena cava injuries. Eur J Vasc Endovasc Surg 2005:30:499-503.

54 Sikhondze WL, Madiba TE, Naidoo NM, Muckart DJJ. Predictors of outcome in patients requiring surgery for liver trauma. Injury 2007:38:65-70.

55 Chalya PL, Kanumba ES, Mabula JB, Giiti G, Gilyoma JM. Aetiological spectrum, injury characteristics and treatment outcome of head injury patients at Bugando medical centre in north-western Tanzania. Tanzan J Health Res 2011;13:74-81.

56 Chalya PL, Gilyoma JM. The burden of intentional injuries in Mwanza City, north-western Tanzania: a tertiary hospital survey. Tanzan J Health Res 2012;14:204-11

57 Jamulitrat S, Sangkerd P, Thongpiyapoom S, Na Narong M. A comparison of mortality predictive abilities between NISS and ISS in trauma patients. J Med Assoc Thai 2001:84:1416-21.

58 Wuthisuthimethawee P. Trauma team activation criteria in managing trauma patients at an emergency room in Thailand. Eur J Trauma Emerg Surg 2017:43:53-7

59 Karbakhsh M, Zandi NS, Rouzrokh M, Zarei MR. Injury epidemiology in Kermanshah: the National trauma project in Islamic Republic of Iran. East Mediterr Health J 2009;15:57-64.

60 Bahloul M, Chelly H, Ben Hmida M, Ben Hamida C, Ksibi H, Kallel H, Chaari A, Kassi M, Rekik N, Bouaziz M, et al. Prognosis of traumatic head injury in South Tunisia: a multivariate analysis of 437 cases. J Trauma 2004;57:255-61.

61 Bahloul M, Ben Hamida C, Chelly H, Chaari A, Kallel H, Dammak H, Rekik N, Bahloul K, Ben Mahfoudh K, Hachicha M, et al. Severe head injury among children: prognostic factors and outcome. Injury 2009;40:535-40.

62 Wang YX, Xu XY, Su WL, Wang Q, Zhu WX, Chen F, Jin G, Liu YJ, Li YD, Sun YP, et al. Activation and clinical significance of p38 MAPK signaling pathway in patients with severe trauma. J Surg Res 2010;161:119-25.

63 Tamim H, Al Hazzouri AZ, Mahfoud Z, Atoui M, El-Chemaly S. The injury severity score or the new injury severity score for predicting mortality, intensive care unit admission and length of hospital stay: experience from a university hospital in a developing country. Injury 2008;39:115-20.

64 Ghodsi SM, Roudsari BS, Abdollahi M, Shadman M. Fall-Related injuries in the elderly in Tehran. Injury 2003;34:809-14.

65 Adesunkanmi AR, Oginni LM, Oyelami OA, Badru OS. Road traffic accidents to African children: assessment of severity using the injury severity score (ISS). Injury 2000:31:225-8.

66 Muckart DJ, Bhagwanjee S, Gouws E. Validation of an outcome prediction model for critically ill trauma patients without head injury. J Trauma 1997;43:934-8. discussion 938-939.

67 Cheddie S, Muckart DJJ, Hardcastle TC, Den Hollander D, Cassimjee H, Moodley S. Direct admission versus inter-hospital transfer to a level I trauma unit improves survival: an audit of the new Inkosi Albert Luthuli central Hospital trauma unit. S Afr Med J 2011;101:176-8.

68 Mnguni MN, Muckart DJJ, Madiba TE. Abdominal trauma in Durban, South Africa: factors influencing outcome. Int Surg 2012;97:161-8.

69 Chalya PL, Mabula JB, Ngayomela IH, Mbelenge N, Dass RM, Mchembe M, Ngallaba SE, Gilyoma JM. Geriatric injuries among patients attending a regional hospital in Shinyanga Tanzania. Tanzan J Health Res 2012;14:15-20.

70 MacLeod JBA, Kobusingye O, Frost C, Lett R, Kirya F, Shulman C. A comparison of the Kampala trauma score (KTS) with the revised trauma score (Rts), injury severity score (ISS) and the TRISS method in a Ugandan trauma registry: is equal performance achieved with fewer resources? Eur. J Trauma 2003:29:392-8.

71 Machemehl T, Hsu P, Pahad H, Williams P, Yilmaz TH, Vassiliu P, Boffard KD, Degiannis E, Doll D. Haemodialysis for post-traumatic acute renal failure - factors predicting outcome. S Afr Med J 2013;103:652-7.

72 Odebode TO. Age related pattern and outcome of head injury in Indigenous Africa. Niger J Clin Pract 2008;11:265-9.

73 Hung YW, He H, Mehmood A, Botchey I, Saidi H, Hyder AA, Bachani AM. Exploring injury severity measures and in-hospital mortality: a multi-hospital study in Kenya. Injury 2017;48:2112-8
74 Burstein B, Fauteux-Lamarre E, As ABvan, van AAB. Increased morbidity associated with weekend paediatric road traffic injuries: 10-year analysis of trauma registry data. Injury 2016;47:1236-41.

75 Goel A, Kumar S, Bagga MK. Epidemiological and trauma injury and severity score (TRISS) analysis of trauma patients at a tertiary care centre in India. Natl Med J India 2004; 17:186-9.

76 Leong BK, Mazlan M, Abd Rahim RB, Ganesan D. Concomitant injuries and its influence on functional outcome after traumatic brain injury. Disabil Rehabil 2013;35:1546-51.

77 Arreola-Risa C, Mock CN, Padilla D, Cavazos L, Maier RV, Jurkovich GJ. Trauma care systems in urban Latin America: the priorities should be prehospital and emergency room management. J Trauma 1995;39:457-62.

78 Wesson HKH, Bachani AM, Mtambeka P, Schulman D, Mavengere C, Stevens KA Millar AJW, Hyder AA, van As AB. Pediatric burn injuries in South Africa: a 15-year analysis of hospital data. Injury 2013:44:1477-82

79 Haac B, Varela C, Geyer A, Cairns B, Charles A. The utility of the Kampala trauma score as a triage tool in a sub-Saharan African trauma cohort. World J Surg 2015;39:356-62

80 Lone GN, Peer GQ, Warn KA, Bhat AM. An experience with abdominal trauma in adults in Kashmir. JK-Practitioner 2001

81 Chalya PL, Mabula JB, Giiti G, Chandika AB, Dass RM, McHembe MD, Gilyoma JM. Splenic injuries at Bugando medical centre in northwestern Tanzania: a tertiary hospital experience. BMC Res Notes 2012;5:59.

82 Owor G, Kobusingye OC. Trauma registries as a tool for improved clinical assessment of trauma patients in an urban African Hospital. East Cent African J Surg 2001:6:57-63.

83 Chalya PL, Mabula JB, Dass RM, Mbelenge N, Ngayomela IH, Chandika AB, Gilyoma JM. Injury characteristics and outcome of road traffic crash victims at Bugando medical centre in northwestern Tanzania. J Trauma Manag Outcomes 2012;6:1

84 Chalya PL, Mabula JB. Abdominal trauma experience over a two-year period at a tertiary hospital in northwestern Tanzania: a prospective review of 396 cases. Tanzan J Health Res 2014:15:1-13.

85 Boniface R, Museru L, Kiloloma O, Munthali V. Factors associated with road traffic injuries in Tanzania. Pan Afr Med J 2016:23:46.

86 Macleod JBA, Kobusingye 0, Frost C. Kampala trauma score (KTS): is it a new triage tool? East cent. African J Surg 2007:12:74-82

87 Mutooro SM, Mutakooha E. Comparison of Kampala trauma score II with the new injury severity score in Mbarara university teaching hospital in Uganda. East Cent African J Surg 2010;15:62-71.

88 Hsia RY, Ozgediz D, Mutto M, Jayaraman S, Kyamanywa P, Kobusingye OC. Epidemiology of injuries presenting to the National hospital in Kampala, Uganda: implications for research and policy. Int J Emerg Med 2010;3:165-72.

89 Rabbani A, Moini M. Application of "Trauma and Injury Severity Score" and "A Severity Characterization of Trauma" score to trauma patients in a setting different from "Major Trauma Outcome Study". Arch Iran Med 2007:10:383-6.

90 Eisenberg RL. TRISS methodology in penetrating trauma: 198 patients at Baragwanath Hospital. Aust N Z J Surg 1993:63:515-9.

91 Buntman AJ, Yeomans KA. The effect of air medical transport on survival after trauma in Johannesburg, South Africa. S Afr Med J 2002:92:807-11.

92 Jamulitrat S, Narong MN, Thongpiyapoom S. Trauma severity scoring systems as predictors of nosocomial infection. Infect Control Hosp Epidemiol 2002:23:268-73.

93 Domingues CdeA, Coimbra R, Poggetti RS, Nogueira LdeS, Sousa RMC. Performance of new adjustments to the TRISS equation model in developed and developing countries. World J Emerg Surg 2017:12:17.

94 Chardoli M, Rahimi-Movaghar V. Analysis of trauma outcome at a university hospital in Zahedan, Iran using the TRISS method. East Afr Med J 2006;83:440-2.

95 Kirya FM, Kijjambu S, Ezati I. Outcome of major trauma at Mulago hospital in Uganda. assessment using the TRISS methodology, Association of Surgeons of East Africa and College of Surgeons of East Central and Southern Africa. 2002. https:// tspace. library.utoronto.ca/handle/1807/19868 (Accessed 13 Mar 2018).

96 Podang J, Singhasivanon P, Podhipak A, Santikarn C, Sarol JN, Ancheta CA. Primary verification: is the TRISS appropriate for Thailand? Southeast Asian J Trop Med Public Health 2004:35:188-94.

97 Hanche-Olsen TP, Alemu L, Viste A, Wisborg T, Hansen KS. Trauma care in Africa: a status report from Botswana, guided by the World Health Organization's "Guidelines for Essential Trauma Care". World J Surg 2012;36:2371-83.

98 Mock C, Nguyen S, Quansah R, Arreola-Risa C, Viradia R, Joshipura M. Evaluation of trauma care capabilities in four countries using the WHO-IATSIC guidelines for essential trauma care. World J Surg 2006:30:946-56.

99 Ouédraogo N, Niakara A, Simpore A, Barro S, Ouédraogo H, Sanou J. [Intensive care in Africa: a report of the first two years of activity of the intensive care unit of Ouagadougou national hospital (Burkina Faso)]. Sante 2002;12:375-81.

100 Zwi KJ, Zwi AB, Smettanikov E, Söderlund N, Logan S. Patterns of injury in children and adolescents presenting to a South African township health centre. Injury Prevention 1995;1:26-30 http://www.ncbi.nlm.nih.gov/pubmed/9345989.

101 Damsere-Derry J, Ebel BE, Mock CN, Afukaar F, Donkor P. Pedestrians' injury patterns in Ghana. Accid Anal Prev 2010;42:1080-8. 
102 Forgus S, Delva W, Hauptfleisch C, Govender S, Blitz J. Community V. non-community assault among adults in Khayelitsha, Western Cape, South Africa: a case count and comparison of injury severity. S Afr Med J 2014;104:299-301.

103 Chichom Mefire A, Etoundi Mballa GA, Azabji Kenfack M, Juillard C, Stevens K. Hospital-Based injury data from level III institution in Cameroon: retrospective analysis of the present registration system. Injury 2013;44:139-43.

104 Afuwape 00, Okolo CA, Akinyemi OA. Preventable trauma deaths in Ibadan: a comparison of revised trauma score and panel review. West Afr J Med 2011;30:19-23.

105 Boschini LP, Lu-Myers Y, Msiska N, Cairns B, Charles AG. Effect of direct and indirect transfer status on trauma mortality in sub Saharan Africa. Injury 2016;47:1118-22.

106 Zargar M, Modaghegh M-HS, Rezaishiraz H. Urban injuries in Tehran: demography of trauma patients and evaluation of trauma care. Injury 2001;32:613-7.

107 Onwudike M, Olaloye OA, Oni 00. Teaching hospital perspective of the quality of trauma care in Lagos, Nigeria. World J Surg 2001;25:112-5.

108 Elkheir N, Sharma A, Cherian M, Saleh OA, Everard M, Popal GR, Ibrahim AA. A cross-sectional survey of essential surgical capacity in Somalia. BMJ Open 2014;4:e004360

109 Saidi HS. Initial injury care in Nairobi, Kenya: a call for trauma care regionalisation. East Afr Med J 2003;80:480-3.

110 Memon AA, Zafar H, Raza R, Murtaza G. Traumatic pancreatic injury--an elusive diagnosis: experience from a developing country urban trauma referral centre. J Pak Med Assoc 2013;63:440-4.
111 öztürk H, Dokucu Al, Otcu S, Onen A. The prognostic importance of trauma scoring systems for morbidity in children with penetrating abdominal wounds: 17 years of experience. J Pediatr Surg 2002;37:93-8.

112 Otieno T, Woodfield JC, Bird P, Hill AG. Trauma in rural Kenya. Injury 2004;35:1228-33.

113 Samuel JC, Akinkuotu A, Baloyi P, Villaveces A, Charles A, Lee CN, Miller W, Hoffman IF, Muyco AP. Hospital-Based injury data in Malawi: strategies for data collection and feasibility of trauma scoring tools. Trop Doct 2010;40:98-9.

114 Honarmand A, Safavi M. The new injury severity score: a more accurate predictor of need ventilator and time ventilated in trauma patients than the injury severity score. Ulus Travma Acil Cerrahi Derg 2008;14:110-7.

115 Mock CN, nii-Amon-Kotei D, Maier RV. Low utilization of formal medical services by injured persons in a developing nation: health service data underestimate the importance of trauma. J Trauma 1997;42:504-11. discussion 511-3.

116 Afuwape 0 , Alonge T. An audit of gunshot injuries seen in the accident and emergency department of a Nigerian tertiary hospital. West Afr J Med 2006;25:295-7.

117 Chalya PL, Mabula JB. Abdominal trauma experience over a two-year period at a tertiary hospital in north-western Tanzania: a prospective review of 396 cases. Tanzan J Health Res 2013;15:230-9. 